\title{
3 Researc Sguare

\section{Intensifying Camel Productivity through Integrated Control of Surra within the Somali ecosystem of the Horn of Africa}

Abdullahi Sheikh Mohamed Nuur ( $\square$ abdullahishemad@gmail.com )

NA

Mousa Mohamed Awale

NA

Abdullahi A. Hersi

NA

Ismail A. Awale

NA

Nashaad Fa. Awale

NA

Yasir Hu. Ali

NA

Mohamoud Yu. Ismail

NA

Judith K. Chemuliti

NA

\section{Research Article}

Keywords: Trypanoma evansi, Prevalence, camel, vectors, Somaliland, Somalia

Posted Date: February 7th, 2022

DOl: https://doi.org/10.21203/rs.3.rs-1254374/v1

License: (c) (7) This work is licensed under a Creative Commons Attribution 4.0 International License.

Read Full License 


\section{Abstract}

A two phase (10 November to 21 December 2019 dry season, and 6 June to 11 July 2021 rainy season) cross sectional Parasitological, Haematological and Entomological survey was carried out in Somaliland's Saahil and Togdheer regions. A total of 390 and 395 camels were bled during first and second phase respectively to determine the prevalence of camel trypanosomosis and trap transmitting vectors. Thin and thick smears from Buffy coat and from direct venous blood samples were screened. Out of 390 , only 2 camels $(0.5 \%)$ from Saahil region were positive in first phase while out of 395,68 camels, 67 Saahil and 1 Togdheer (17.2\%) were positive in second phase. Prevalence of Trypanosoma evansi (T. evansi) infection recorded were (10.6\%), (5.3\%) and 1.3\% for camels with poor, fair and good body conditions respectively and were statistically significant $(P=0.002)$. No significant prevalence differences between sex and age recorded. Micro-hematocrit method was used to determine packed cell volume (PCV). Animals with (PCV) $<25 \%$ were considered anemic and prevalence was negatively correlated to PCV. Biting flies (vectors) were trapped using NZI trap. Traps were set and emptied 48 hours post setting in both regions and phases. Two families of vectors- Tabanidae and Muscidae were identified. The study revealed camel trypanosomosis is enzootic in the region. The disease and its vectors are strongly related to ecology and season.

\section{Introduction}

In Somali eco-system, communities rear a substantial number of camels for subsistence. Camels are reared mainly for milk and meat. Because of its resistance to harsh environments and can stay long without water, camel rearing is significant for food security in pastoral systems. In addition to its nutritional value, camel milk became popular for its reported medicinal value. Regular consumption is said to help in optimal management of diabetes besides helping in controlling high blood pressure (Askale and Samson 2017). Camel milk has anti-bacterial and anti-viral qualities that assist the body to fight diseases (Devandra et al. 2016). Actual camel population in Somalia is not known. Food and Agricultural Organization (FAO) estimated camel population in 1986 to be around 5,750,000 (Payne 1990). However, camel production is hampered by diseases inflicting serious economic loss to pastoralists.

The epidemiology of many animal diseases results from interactions between vectors such as ticks, haematophagus biting flies, climate, and susceptibility of host species, animal movement and stress. Domestic and wild animal populations carry disease agents as reservoirs in a habitat.

Haematophagus, Diptera (Tabanidae) mechanically transmitting camel trypanosomosis are reported to be present in Somaliland (Diriye 1989). In addition to trypanosomosis, Tabanidae can potentially transmit many other infectious diseases (Coetzer and Tustin 2004).

Opportunities to improve camel reproductive and productive efficiency are limited by many factors including wasting diseases. Amongst dangerous camel wasting disease is trypanosomosis (Payne 
1990). Camel T. evansi infection which is transmitted mechanically by Tabanidae and other flies is enzootic in Somali ecosystem (Edelsten 1995) where camel herds severely suffer manifesting with reduced production (meat and milk) and reproduction.

Thus, T. evansi infection seriously affects household sustenance in terms of reduced animal population and products of animal origin as well as cost of treatment and prophylactic interventions. Other domestic animals with variable clinical manifestations suffer as well with decreasing production, growth and power. T. evansi has a very vast host range including camels, equids, sheep, goat, cattle and buffalo and other wildlife (Sewell and Brocklesby 1990). To increase and expand its host range, T.evansi started infecting also humans (Prashant P. et al. 2005)

Accurate diagnosis of this disease is important for livestock stakeholders especially the producers in order to treat and control where the disease is enzootic and prevent from where is not present. However, because of the low sensitivity of the traditional parasitological methods, detection of the disease is not easy and a negative parasitological examination does not necessarily mean that the animal is not infected.

Statement of the problem: The first and foremost sign of camel trypanosomosis according to Somali pastoralists is sudden drop of milk production in the female and break of rut (breeding activity) in the male. The sudden drop of milk has a serious impact on household sustenance because children will miss milk - their primary stable food and impacts on the surplus that could be sold for cash. All other clinical signs such as lacrimation, anemia, lymph node swelling, emaciation, ventral abdominal oedema, neurological problem, and sometimes, abortion and death come after this major sign which alerts pastoralists about an outbreak of trypanosomosis on which they decide whether to move the camels to a safe place or keep them there and face the risk.

Both curative and prophylactic treatments of camel trypanosomosis are becoming expensive with huge burden on the camel herders in terms of cost of purchasing in addition to non quality drugs, and increasing resistance of Trypanosoma evansi against trypanocidal drugs (El Rayah et al. 1999) and (Jinlin et al. (2004) leading to less effective treatments.

Types, abundance, and distribution of transmitting vectors of camel trypanosomosis are still not well studied, thus, not well known in Somalia/Somaliland. This makes the epidemiology and eventually possible strategic intervention and control of the disease remain difficult.

Since animal diseases are somehow dynamic with host availability, climate and ecological changes, this study intends to study the prevalence of camel trypanosomosis, and investigate and map the spatial and temporal variation of vectors and evaluate influence on the epidemiology of the disease in order to possibly suggest environmentally friendly vector control methods to alleviate the huge loss incurred by camel herders.

\section{Materials And Methods}


Study sites: Saahil and Togdheer regions of Somaliland Figure 1

The study was carried out in the two administrative Saahil and Togdheer regions of Somaliland from (10 November to 21 December 2019 (dry season) and 06 June to 11 July 2021 (rainy season) between latitudes of $\left(10.88686^{\circ}-10.501362^{\circ}\right) \mathrm{E}$, longitudes $\left(45.43265^{\circ}-44.823402^{\circ}\right) \mathrm{W}$ and an elevation/altitude of between $2 \mathrm{~m}-876 \mathrm{~m}$ above sea level for Saahil region, and between latitudes of $\left(9.811323^{\circ}-9.633420^{\circ}\right)$ $\mathrm{E}$, longitudes of $\left(46.114562^{\circ}-45.360693^{\circ}\right)$ and an elevation/altitude between $932 \mathrm{~m}$ to $1229 \mathrm{~m}$ above seas level for Togdheer region. Generally, Saahil region is rocky and mountainous, mostly sandy in the coastal area with sparse vegetation and hot with temperatures between $28-32^{\circ} \mathrm{C}$ on averages which reaches $40^{\circ} \mathrm{C}$ in coastal areas, while Togdheer region relatively less mountainous, mostly green plateau with relatively high density of shrubs, grass land and different trees with an average temperature of between $\left(17-29^{\circ} \mathrm{C}\right)$. The lowest value in the country's Relative humidity of about (40\%) occurs within Togdheer region. Wind speed ranges between 8 to 11 meters per second in June July at areas of Toghdeer region Somalia Water and Land Information Management (SWALIM) (2007). But these meteorological parameters usually change season by season.

Animals graze during the rainy season when temperatures are relatively low $15-25^{\circ} \mathrm{C}$ and move within coastal areas from place to place depending on vector challenge during rainy seasons. Animals however move to highland areas in Togdheer region when the climate becomes too hot and windy in Saahil tregion. Noteworthy is that the spring (rainy season) of 2021 was too short compared to normally known pattern. By late May rains stopped.

Sampling Design: A stratified random sampling technique was used in order to get optimal representation of the expansive administrative regions. In each administrative region, three clusters were stratified based on their proximity to urban centers with animal health infrastructure, most commonly the district headquarters. The study sites (villages) within $20 \mathrm{~km}$ of the regional headquarters (Berbera for Saahil and Burao for Togdheerare considered to form cluster one, those within $20-50 \mathrm{~km}$ of the regional headquarters form cluster two while those that are more than $50 \mathrm{~km}$ from the regional headquarters form cluster three. Three study sites (locations/settlements) have been randomly selected from each cluster, for a total of 9 sites in each region conditions permitting. Selected villages were geo-referenced. Locations where livestock owners reject cooperation will be replaced with the nearest location possible.

Sample size determination: In each cluster locations, a random sampling technique has been used to recruit animals for the study after the approval of the owners. The sample size was calculated as recommended by (Thrusfield 2005), assuming an expected prevalence of $50 \%$, a $5 \%$ absolute precision and $95 \%$ confidence interval. Therefore, the calculated sample size was 386 camels. The number of animals to be sampled was distributed to the three sampling clusters based on the estimated population of animals in each village and location.

Examination of selected animals: At each selected site, information on the livestock keeper's details (name, address, and where practical, phone number and herd characteristics (herd size, numbers of adult males, females and young stock) were collected followed by documentation of detailed case histories for 
all camels selected for veterinary examination and sampling. Complete records of these data are kept for subsequent analysis. Estimation of body weight and body condition score was carried out by visual appraisal. In addition, discussions were held with the elders and pastoralists on their knowledge on the disease, its causes and the vectors. Camel herd compositions were visually estimated, because culturally pastoralists are reluctant to provide information on herd size as this considered a sensitive matter and are reluctant to share such information with strangers. Camels below 2 year were considered as calves, those between 2-4 years as young, while those above 4 years of age were considered adults.

Blood sample collection: Blood samples were collected for confirmatory diagnosis. A total of $5 \mathrm{ml}$ of blood was collected from the jugular veins of all selected camels using Ethylenediaminetetraacetic acid (EDTA) vacutainer tubes. The whole blood in EDTA sample was divided into two aliquots, each $2.5 \mathrm{ml}$. One of the $2.5 \mathrm{ml}$ aliquot was used for parasitological examination (PCV) determinations. Parasitological examinations were carried out using a combination of Gram stained thin and thick blood smears (TTBS) after concentration of trypanosomes by the micro-haematocrit centrifuge technique (MCHC) recommended by (Woo 1969) and a direct Gram stained wet (TTBS) without concentration. Animals with $(\mathrm{PCV})<25 \%$ were considered anemic as recommended by (Gerem et al. 2020).

Setting NZI Traps: A total of 62 (33 and 29) traps and 64 (34 and 30) traps were set up in the six clusters of Saahil and Togdheer in first and second phase respectively. Traps were set and emptied 48 hours post setting. Three weeks old cow urine was used as attractant. Grease was applied at the bottom of the pole to prevent attack from predator insects.

Data analysis: Data was analyzed using Jamovi 1.2.27 statistical software. Tabular data were exported to Microsoft word tables. And figures were created using Jamovi 1.2.27 statistical software.

Biting flies were classified and identified up to genera level using the three volumes of

Oldroyd, H. (1952) The horse-flies (Diptera: Tabanidae) of the Ethiopian Region. Volume I. Haematopota and Hippocentrum. British Museum Natural History

Oldroyd, H. (1954) The horse-flies (Diptera: Tabanidae) of the Ethiopian Region. Volume II. Tabanus and related Genera. British Museum Natural History

Oldroyd, H. (1957) The horse-flies (Diptera: Tabanidae) of the Ethiopian Region. Volume III. Subfamilies. And Stereomicroscope model GX CEROHSFC

\section{Results}

In phase one, out of 392 (202 Saahil and 190 Togdheer) camel blood samples examined, only 2 positive $(0.5 \%)$ samples were recorded from Saahil region as depicted in Table 1.

Regarding vectors, seventy-one (71) biting flies were trapped during first phase survey. Vector and distribution by region and by village are shown in Table 2 . 
In second phase, out of 395 camel blood examined, 68 (67 Saahil and only 1 Togdheer) (17.2\%) were positive for Trypanosomosis as shown in Table 3.

Prevalence of Trypanosoma evansi infection and associated risk factors: The prevalence of T.evansi infection in camels was compared based on sex, age group, body condition, and anemic status risk factors as shown in Table 4. The prevalence in males was lower (4.1\%) compared to the females (13.2\%) which was not statistically significant $(P=0.468)$ as usual because most camels are sold for cash. Adults were more affected (10.6\%) than calves and young camels with prevalence's of $(4.6 \%)$ and $(2.0 \%)$ respectively which also was not statistically significant $(P=0.453)$. Regarding body condition, the prevalence was $10.6 \%, 5.3 \%$ and $1.3 \%$ among camels with poor, fair and good body conditions respectively. The difference was statistically significant $(P=0.002)$.

Camels with very poor and very good body conditions were both negative. According to the state of anemia, the prevalence among anemic and non-anemic camels was $17 \%$ and $0.3 \%$ respectively. The difference was statistically significant $(P<.001)$.

The prevalence is negatively correlated to PCV, as shown by Figure 2. As the PCV scale reading increases, the positivity decreases. This means that a low PCV reading indicates anaemia hence can be used as an indicator of Trypanosomosis in risky areas where the disease is enzootic with vector presence. No correlation was observed between age and PCV.

Regarding vectors, in phase two 117 (111 Tabanidae and 6 Muscidae from Saahil) and none (0) from Togdheer were collected as shown by Table 5 .

\section{Discussion}

In the first phase (dry season) of this study, was recorded prevalence of $2(0.5 \%)$ in Saahil and zero (0) in Togdheer respectively. While in second phase (rainy season), prevalence of $67(17 \%)$ in Saahil and 1 $(0.3 \%)$ in Togdheer region respectively were recorded. Among Sahel villages, Batalaale had the highest prevalence followed by Geel-lokor, Bixin, Xeedho and Hudusa with respective rates of 26 (6.6\%), 14(3.5\%), $11(2.8 \%), 10(2.5 \%), 6(1.5 \%)$, while in Togdheer region, the sole positive case $1(0.3 \%)$ was from Cadawyurura village. This could be attributed to higher vector challenge in Saahil than in Togdheer because in Saahil region were found Tabanidae and Muscidae families in both phases while in Togdheer, only Muscidae family was found only in first phase. No Philoliche was trapped in first phase (Table2) while it was the prominent vector in second phase (Table 5). This trend is explained by the ecological differences of the two regions in one hand and the relative resistance of vectors to heat and wind on the other. The Golis range of Saahil region acting as strong wind barrier in addition to availability of continuous streams provide conducive environment for vectors survival year round. Vector challenge is higher during rainy seasons causing acute form of the disease and low challenge in dry season, maintaining the disease in its chronic form. Contrary to our current finding, (Elamin et al. 1998) reported that the camel T.evansi infection rate was higher during dry period instead of the wet period in Sudan. This is an aspect that needs further investigations as there could be other factors behind this aberration. 
In Hudusa - village at the base of Golis Range Mountains, Philoliche of (Tabanidae family) seriously disturb camels by puncturing the camel belly with their long needle like mouth parts. Since camels don't have long tail to chase the flies, they respond by running to escape from the area causing a lot of animal movement within lowland of Saahil region which is mainly infested by vectors having long piercing proboscides with high transmitting capacity (Philoliche, Tabanus and Haematopota) while Togdheer region is inhabited only by Haematobia of (Muscidae family) which seems relatively cause less disturbance to the camels. It is not clear whether the absence of Tabanidae family from Togdheer region is due to altitude or to low relative humidity. Tabanus genera is spread over large area as it is present in Bixin, Biyooleey, Geel lookor and Hudusa of Saahil region (Table 5) and in both phases. In addition to its wide distribution, Tabanus is the most resistant vector against heat and wind according to pastoralists and it is considered the main vector maintaining the disease feeding on both domestic and wild animals year round in the region. Philoliche appears in abundance only during the first weeks of the rainy season and disappears as shown in (Figure 3).

Haematopota is less resistant to heat and wind compared to Tabanus but more resistant and survives longer than Philoliche but it also disappears later on. Haematobia were caught from both regions during dry season, they may be less important mechanical transmitters especially in camels probably due to the relative camel skin thickness and hardness. The reason why Haematobia was not caught in Togdheer region during the rainy season is that by June, unexpected strong winds started blowing. Traps where found either torn apart on ground or on the trees. There is a clear change of seasonal pattern in the region. This could be one of the consequences of global warming.

The high concentration of Philoliche in Hudusa village at the base of Golis range with a relative low T.evansi infection $6(1.5 \%)$ and high prevalence in T. evansi infection in Batalaale $26(6.6 \%)$ ) and Xeedho10 (2.5\%)) at ocean level with less vector challenge is partially explained by camel movement after being infected in Hudusa and escaped from the high challenge to lower challenge in addition to the mechanical transmission role of Tabanus and possibly Haematobia flies present in this area. (Tadewos Kassa et al. 2011) reported that $99 \%$ of the collected biting flies were Stomoxes in the study area with few Tabanus with low prevalence of (4.7) of camel trypanosomosis in Ethiopia. Furthermore, (Christine et al. 2017) stated that Trypanosoma evansi transmission can be sustained mechanically by Tabanidae and Stomoxys which is same family of Haematobia biting flies.

The prevalence of camel $T$. evansi infection in this study (17.3\%) is higher than $4.4 \%$ reported by (Tadewos Kassa et al. 2011) in Ethiopia and $5.4 \%$ based on parasitological test reported by (Elamin et.al. (1998) in Sudan, but the present prevalence is almost in agreement with the findings of $20.6 \%$ maximum point rate reported by (Zeleke and Bekele 2001) in eastern Ethiopia. Zeleke and Bekele farther reported that T.evansi prevalence is higher in the rainy seasons which is in agreement with this study findings.

The current studies do indicate that both the prevalence of camel trypanosomosis (17.2\%) and its vectors are strongly related to ecology and season. The very low prevalence of T.evansi infection in Togdheer is probably partially due to infected camels movement from Saahil to Togdheer which is possible also to 
other regions Somaliland. The most infested area is the low land of Saahil region where both vectors and disease are inflicting serious decrease of camel production and productivity. It has been observed that vectors move with animals to certain distance within Saahil region. Livestock herders reported that the first wave of vector challenge starts from the valleys where Acacia senegalensis is abundant. The disease and its effects can be reduced by strategic combination and integration of continuous temporal trapping of the vectors in the more infested areas during rainy seasons and prophylactic treatment using appropriate quality drugs possibly covering long period before rains start. Pastoralist training on NZI traps which is the most efficient trap as communal vector control program would significantly reduce the vectors and disease.

\section{Declarations}

Acknowledgements: We thank the Somaliland Ministry of Livestock and Fishery Development for facilitating the research and donated NZI traps. We also thank Dr. Amina Mo. Hussein, Dr. Hibo Ha. Elmi,

We thank also Mr. Abdigani Ma. Mousa for his partial support in the field activity. We acknowledge Mr. Mohamed Aden Ahmed (Guun) IGAD-STVS IT and Data Manager for his support on the geo-referencing, the Map and other logistics. We also thank to those pastoralist community who without hesitance helped the teams in fulfilling their duties

\section{Statements \& Declarations:}

Funding: The research leading to these results received funding from European Union and African Union under Grant Agreement No AURG-II-1-179-2016

Conflicts of interest/Competing interests: The authors have no relevant financial or non-financial interests to disclose

Ethics approval: Approval was granted by IGAD Sheihk Technical Veterinary School (ISTVS) Reference Center (RC) Steering Committee

Consent to participate: Informed consent was obtained from all livestock owners included in the study after jointly explained the objectives of the study by ISTVS and the Somaliland Ministry of Livestock and Fishery Development, and the manuscript does not contain personal data.

Statement of Animal Rights: For the research, authors obtained approval from Somaliland Ministry of Livestock and Fishery Development. Animal rights were strictly observed and always after the consent of the owners

Consent for publication: Not applicable

Availability of data and material (data transparency): The datasets generated during and/or analyzed during the current study are not publicly available only because we are not technologically advanced to create software application or custom code. 


\section{Author Contributions:}

Conception and study design was developed by Dr. Judith K. Chemuliti

Material preparation, field data collection and laboratory investigations were performed by:

Dr. Mousa Mo. Awale, Dr. Ismail A. Awale, Dr. Yasir Hu. Ali, Mrs Nashaad Fa. Awale, Dr. Mohamoud Yu. Ismail

Data analysis was performed by Dr. Mousa Mo. Awale

Vector classification and identification up to genera level was performed by Dr. Abdullahi A. Hersi

The first draft of the manuscript was written by Dr. Abdullahi Sh. Mohamed

All authors read and approved the final manuscript.

\section{References}

1. Askale Abrhaley and Samson Leta 2018. Medicinal value of camel milk and meat, Journal of Applied Animal Research, 46, 552-558

2. Christine M. Kamidi, Norah P. Saarman, Kirstin Dion, Paul O. Mireji, Collins Ouma, Grace Murilla, Serap Aksoy 2017. Multiple evolutionary origins of Trypanosoma evansi in Kenya, PLoS Neglected Tropical Diseases.

3. Coetzer J.A.W and Tustin R. C. 2004. Infectious Diseases of Livestock; Volume One; 2nd edition

4. Devendra Kumarb, Manish Kumar Chatlia, Raghvendar Singhb Nitin Mehtaa and PavanKumara 2016. Antioxidant and antimicrobial activity of camel milk casein hydrolysates and its fractions, Small Ruminant Research, 139, 20-25

5. Edelsten R.M. 1995. Livestock Diseases in the Northern Regions of Somalia; A Report of the British Veterinary Team - condensed version, VETAID, 30 - 32

6. Elamin, E.A, El Bashir M.O.A. and Saeed E.M.A. 1998. Tropical Animal Health and Production, 30, 107-114

7. El Rayah I E, Kaminsky R, C Schmid, K H El Malik 1999. Drug resistance in Sudanese Trypanosoma evansi, Veterinary Parasitology, 4, 281-7

8. Gerem Bekalu \& Yesuf Muhammed \& Assefa Ayalew 2020. Prevalence and Associated Risk Factors of Trypanosoma evansi in Camels in Ethiopia Based on Parasitological Examinations. Veterinary Medicine International, Article ID 6172560

9. Jinlin Zhou, Jie Shen, Dangjin Liao, Yongzhi Zhou, Jiaojiao Lin 2004. Resistance to drug by different isolates Trypanosoma evansi in China, Acta Tropica 3, 271-275

10. Mohamed F. Dirie, K.R. Wallbanks, Abdi A. Aden, S. Bornstein, and M.D. Ibrahim (1989). Camel Trypanosomiasis and its Vectors in Somalia, Veterinary Parasitology, 4, 285-91 
11. Payne W. J.A., 1990. An Introduction to Animal Husbandry in the Tropics, (ELBS, Singapore)

12. Prashant P. Joshi, Vijay R. Shegokar, Rajaram M. Powar, Stephane Herder, Rahul Katti, Harasha R. Salkar, Vibahawari S. Dani, Aradhana Bharagaya, Jean Jannin, and Philippe Truc 2005. Human Trypanosomiasis caused by Trypanomsoma evansi in India, American Journal of Tropical Medicine and Hygiene, 3, 491-5

13. Sewell M.M. H. D.M. Brocklesby 1990. Handbook on Animal Disease in the Tropics, (ELBS Cambridge)

14. Somalia Water and Land Information Management SWALIM 2007. Technical Report No. W-01, Climate of Somalia

15. Tadewos Kassa1, Tadesse Eguale2*, and Hassen Chak 2011 Prevalence of camel trypanosomosis and its vectors in Fentale district, South East Shoa Zone, Ethiopia, VETERINARSKI ARHIV 5, 611-621,

16. Michael Thrusfield 2005. Veterinary Epidemiology, (Blackwell Science, Oxford)

17. Woo P.T.K. 1969. The haematocrit centrifuge for the detection of trypanosomes in the blood. Canadian. Journal of Zoology, 47, 921-924

18. Zeleke M., Bekele T. (2001). Effect of Season on the Productivity of Camels (Camelus dromedarius and the Prevalence of Their Major Parasites in Eastern Ethiopia, Tropical Animal Health and Production, 33, 4, 321-329

\section{Tables}

Table1: Camel herd composition and Trypanosomosis by region and by season 


\begin{tabular}{|c|c|c|c|c|}
\hline \multicolumn{5}{|c|}{ Phase one (dry season) } \\
\hline Region & Total camels per region & \multicolumn{2}{|c|}{ Age group numbers } & Test results \\
\hline \multirow[t]{2}{*}{ Saahil } & \multirow[t]{2}{*}{202} & Adult & 124 & $+\mathrm{Ve}(2)$ \\
\hline & & Calf plus young & 78 & - \\
\hline \multirow[t]{3}{*}{ Togdheer } & \multirow[t]{2}{*}{190} & Adult & 81 & - \\
\hline & & Calf plus young & 109 & - \\
\hline & \multicolumn{2}{|l|}{392} & 392 & - \\
\hline \multicolumn{5}{|c|}{ Phase two (rainy season) } \\
\hline \multicolumn{2}{|l|}{ Region } & \multicolumn{3}{|c|}{ Age group numbers } \\
\hline \multirow[t]{2}{*}{ Saahil } & \multirow[t]{2}{*}{200} & Adult & 114 & \multirow[t]{2}{*}{$+\operatorname{Ve}(67)$} \\
\hline & & Calf plus young & 86 & \\
\hline \multirow[t]{3}{*}{ Togdheer } & \multirow[t]{2}{*}{195} & Adult & 117 & \multirow[t]{2}{*}{$+\mathrm{Ve}(1)$} \\
\hline & & Calf plus young & 78 & \\
\hline & 395 & & 395 & \\
\hline
\end{tabular}

Tab 2: Type and distribution of biting flies by region and by village phase 1 


\begin{tabular}{|c|c|c|c|c|c|}
\hline & & & \multicolumn{3}{|l|}{ Family } \\
\hline & & & \multicolumn{2}{|c|}{ Tabanidae } & Muscidae \\
\hline & & & \multicolumn{2}{|l|}{ Genus } & Genus \\
\hline Region & Village & No of Traps & Tabanus & Haematopota & Haematobia \\
\hline \multirow{6}{*}{ Saahil } & Biyoley & 5 & 5 & & \\
\hline & Batalaale & 7 & 3 & & \\
\hline & Geel-lokor & 5 & 4 & & \\
\hline & Hudusa & 7 & 9 & 3 & \\
\hline & Bixin & 5 & 4 & 3 & \\
\hline & Xeedho & 4 & 1 & & \\
\hline \multirow[t]{7}{*}{ Togdheer } & Bali xaga & 5 & & & 12 \\
\hline & Cadawyurura & 5 & & & 10 \\
\hline & Cali Sahid & 5 & & & 17 \\
\hline & Gabogabo & 3 & & & \\
\hline & Kalasharka & 5 & & & \\
\hline & Madaxweyn & 7 & & & \\
\hline & Total & 62 & 26 & 6 & 39 \\
\hline
\end{tabular}

Table3: The prevalence of Camel Trypanosomosis by region and by village phase 2 


\begin{tabular}{llll} 
Region & Villages & Total Camels Tested & $\begin{array}{l}\text { Prevalence } \\
(\mathbf{n}=395)\end{array}$ \\
\hline \multirow{2}{*}{ Saahil } & Biyoley & 26 & $0(0.0 \%)$ \\
\cline { 2 - 4 } & Batalaale & 54 & $26(6.6 \%)$ \\
\cline { 2 - 4 } & Geel-lokor & 44 & $14(3.5 \%)$ \\
\cline { 2 - 4 } & Hudusa & 40 & $6(1.5 \%)$ \\
\cline { 2 - 4 } & Bixin & 22 & $11(2.8 \%)$ \\
\cline { 2 - 4 } Togdheer & Xeedho & 14 & $10(2.5 \%)$ \\
\cline { 2 - 4 } & Bali xaga & 28 & 0 \\
\cline { 2 - 4 } & Cadawyurura & 56 & $1(0.3 \%)$ \\
\cline { 2 - 4 } & Cali Sahid & 18 & 0 \\
\cline { 2 - 4 } & Gabogabo & 46 & 0 \\
\cline { 2 - 4 } & Kalasharka & 26 & 0 \\
\cline { 2 - 4 } & Madaxweyn & 21 & 0 \\
\hline Total & & 395 & $68(17.2 \%)$ \\
& & & 0
\end{tabular}

Table4: Prevalence of Trypanosomosis by region, age, sex, body condition and anemic status phase 2 


\begin{tabular}{|c|c|c|c|c|}
\hline \multicolumn{2}{|l|}{ Risk Factors } & \multirow{2}{*}{$\begin{array}{l}\text { No. Examined } \\
200\end{array}$} & \multirow{2}{*}{$\begin{array}{l}\text { No. Infected } \\
67(17.0 \%)\end{array}$} & \multirow{2}{*}{$\begin{array}{l}P \text { value } \\
<.001\end{array}$} \\
\hline Region & Saahil & & & \\
\hline & Togdheer & 195 & $1(0.3 \%)$ & \\
\hline \multirow[t]{2}{*}{ Anemic status } & Anemic & 273 & $67(17.0 \%)$ & $<.001$ \\
\hline & Not Anemic & 122 & $1(0.3 \%)$ & \\
\hline \multirow[t]{3}{*}{ Age } & Calves & 97 & $18(4.6 \%)$ & 0.453 \\
\hline & Young & 67 & $8(2.0 \%)$ & \\
\hline & Adult & 231 & $42(10.6)$ & \\
\hline \multirow[t]{2}{*}{ Sex } & Female & 288 & $52(13.2)$ & 0.468 \\
\hline & Male & 107 & $16(4.1 \%)$ & \\
\hline \multirow[t]{5}{*}{ Body Condition Score } & Very Good & 1 & 0 & 0.002 \\
\hline & Good & 43 & $5(1.3 \%)$ & \\
\hline & Fair & 191 & $21(5.3 \%)$ & \\
\hline & Poor & 157 & $42(10.6 \%)$ & \\
\hline & Very Poor & 3 & 0 & \\
\hline
\end{tabular}

Table 5: Types, number and distribution of vectors by region and by village phase 2 


\begin{tabular}{|c|c|c|c|c|c|c|}
\hline & & & \multicolumn{4}{|l|}{ Family } \\
\hline & & & \multicolumn{3}{|l|}{ Tabanidae } & Muscidae \\
\hline & & & \multicolumn{3}{|l|}{ Genus } & Genus \\
\hline Region & Village & No of Traps & Philoliche & Tabanus & Haematopota & Haematobia \\
\hline \multirow{6}{*}{ Saahil } & Biyoley & 7 & 3 & 3 & 0 & 0 \\
\hline & Batalaale & 5 & 0 & 0 & 0 & 5 \\
\hline & Geel-lokor & 5 & 0 & 2 & 0 & 0 \\
\hline & Bixin & 6 & 0 & 4 & 0 & 0 \\
\hline & Hudusa & 5 & 89 & 8 & 1 & 0 \\
\hline & Xeedho & 6 & 0 & 1 & 0 & 1 \\
\hline \multirow[t]{7}{*}{ Togdheer } & Bali xaga & 4 & 0 & 0 & 0 & 0 \\
\hline & Cadawyurura & 5 & 0 & 0 & 0 & 0 \\
\hline & Cali Sahid & 5 & 0 & 0 & 0 & 0 \\
\hline & Gabogabo & 7 & 0 & 0 & 0 & 0 \\
\hline & Kalasharka & 6 & 0 & 0 & 0 & 0 \\
\hline & Madaxweyn & 3 & 0 & 0 & 0 & 0 \\
\hline & Total & 64 & 92 & 18 & 1 & 6 \\
\hline
\end{tabular}

Figures 


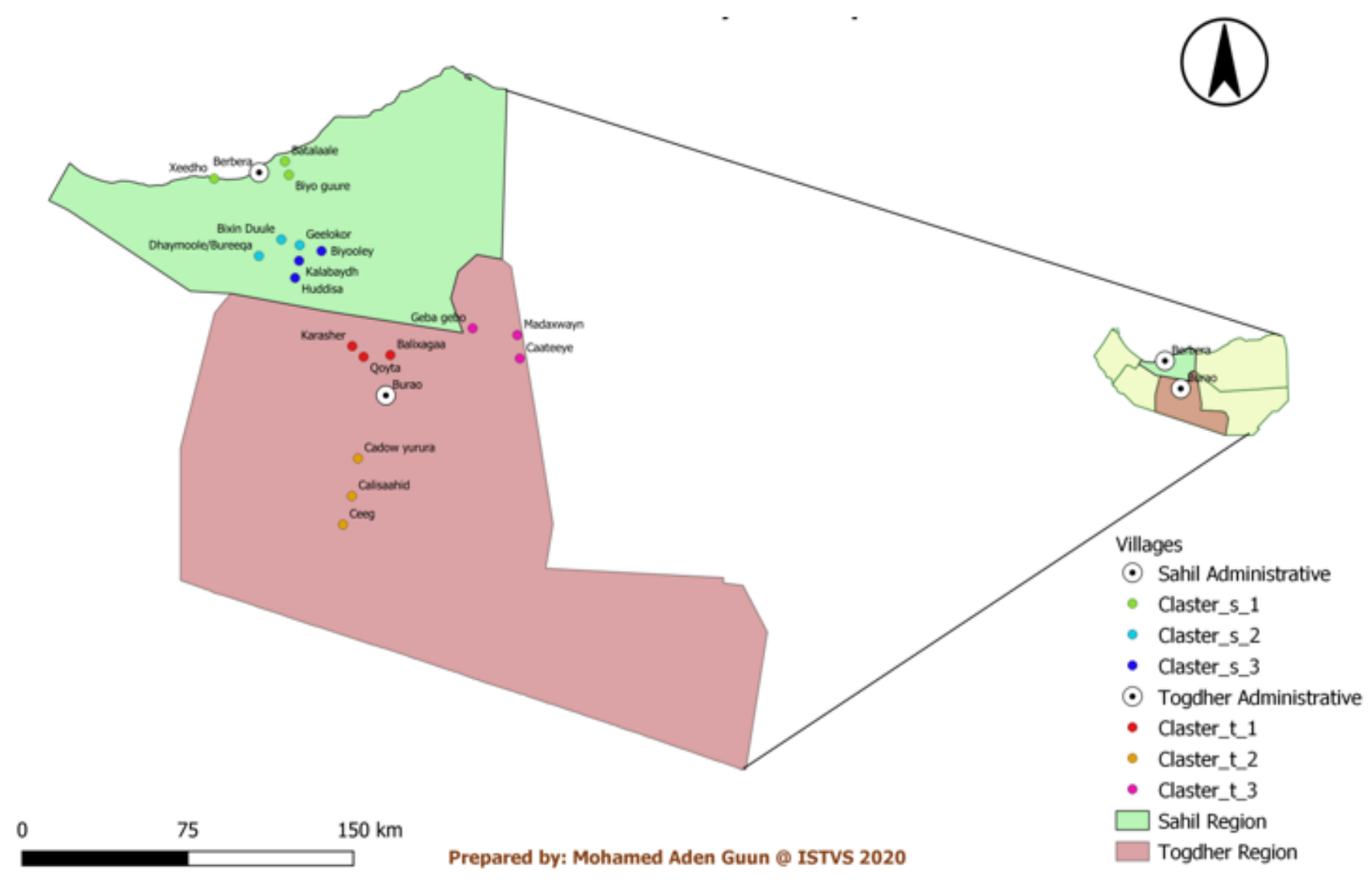

Program used: QGIS 3.2.1

Figure 1

Study sites: Sahil and Togdheer regions of Somaliland 


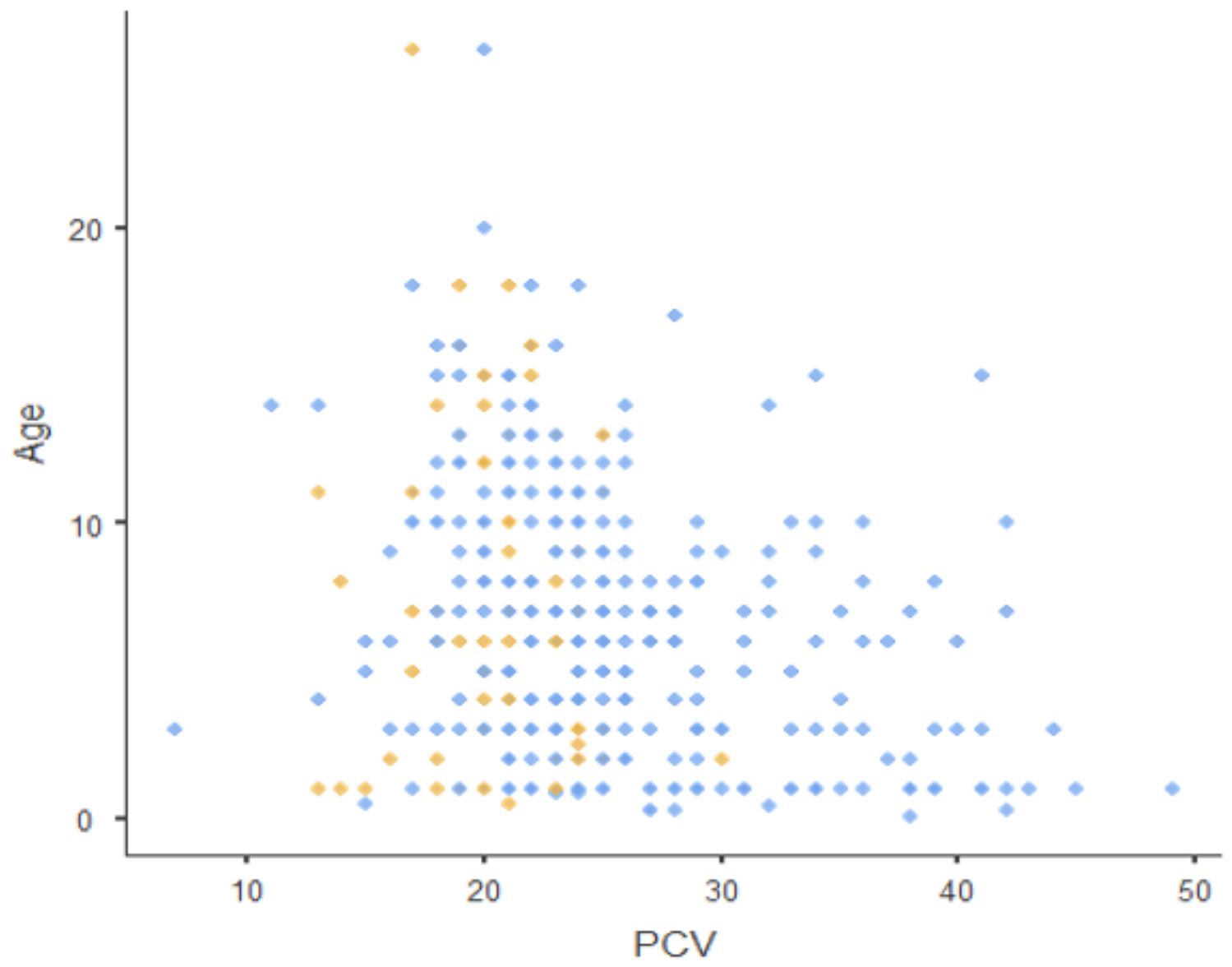

Findings

- 0

- 1

Figure 2

Correlation between prevalence and PCV ( 1 is positive and 0 negative) 


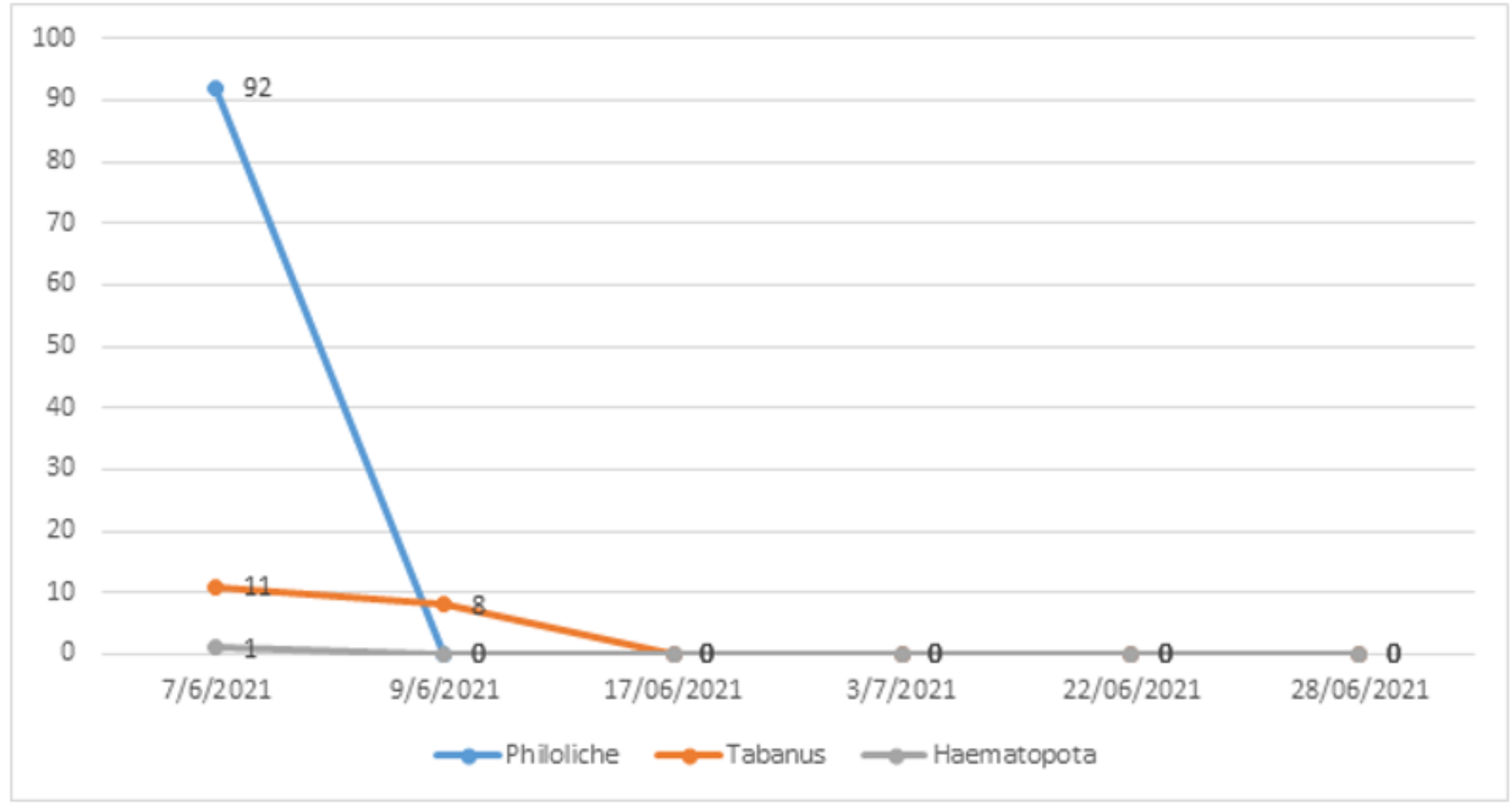

Figure 3

Vector behavior 